\title{
Aprendizagens partilhadas: $O$ uso da tecnologia por um deficiente visual aos seus professores na educação superior
}

\author{
Natália Hends de Medeirois ${ }^{1}$, Miguel Arcanjo da Crus Silva ${ }^{2}$ \\ ${ }^{1}$ Pedagoga - Faculdade Mario Quintana (FAMAQUI) - Porto Alegre - RS - Brazil \\ ${ }^{2}$ Professor e Diretor - Faculdade Mario Quintana (FAMAQUI) - Porto Alegre - RS - \\ Brazil \\ natalia_hends@yahoo.com.br,arcanjomcs@gmail.com
}

\begin{abstract}
The article deals with a research investigated as an exploratory case study, which involves the discussion of the sharing of experience on pedagogical actions with teachers about the use of technology by a visually impaired student to their teachers in higher education. The authors who guided the research were Mantoan (2011), Rosito and Scariot (SBIE 2012), Rosito and Roman (SBIE 2012) and Silva, Façanha, Viana, Castro Filho and Sánchez (2014). The results pointed out that teachers who work with students with visual impairment in Higher Education have in their pedagogic work organization the need for pedagogical knowledge in the use of technologies and this support may come from the sharing of experience developed by a visually impaired student to construct Learning strategies on the use of technology in inclusion processes.
\end{abstract}

Resumo. $O$ artigo trata de uma pesquisa investigada como estudo de caso exploratório, que envolve a discussão da partilha de experiência sobre ações pedagógicas sobre o uso da tecnologia por uma aluna deficiente visual aos seus professores na educação superior. Os autores que orientaram a pesquisa foram Mantoan (2011), Rosito e Scariot (SBIE 2012), Rosito e Roman (SBIE 2012) e Silva, Façanha, Viana, Castro Filho e Sánchez (2014). Os resultados apontaram que os professores que atuam com alunos com deficiência visual na Educação Superior tem na prática da sua organização do trabalho pedagógico a necessidade do conhecimento pedagógica no uso das tecnologias e este apoio pode advir da partilha de experiencia desenvolvida por aluno deficiente visual para construir estratégias de aprendizagens sobre o uso da tecnologia nos processos de inclusão.

\section{Apresentação}

Percebemos que a trajetória de ações pedagógicas com professores vem sendo identificada em pesquisas pelo uso da tecnologia onde busca o desenvolvimento da aprendizagem para potencializar a construção de desafios. Molin e Raabe (2012) investigaram as percepções de um grupo de professores sobre possíveis transformações ocorridas em suas práticas pedagógicas após terem participado do Curso de Formação Continuada "Introdução à Educação Digital." Ribeiro, Vieira e Geraldo (CBIE 2014) desenvolveram pesquisa sobre a utilização das salas virtuais produzidas como recurso 
VI Congresso Brasileiro de Informática na Educação (CBIE 2017)

Anais dos Workshops do VI Congresso Brasileiro de Informática na Educação (WCBIE 2017)

para a formação continuada de educadores. Palazzo, Costa, Dimuro e Schirmbeck (2002) apresentam proposta de metodologia para o desenvolvimento de Comunidade Virtual de Formação Tecnológica.

Essas construções de ações pedagógicas com professores na Educação Superior recebem apoio a uma educação de qualidade por núcleos pedagógicos ${ }^{1}$ Dentre os objetivos de trabalho destes núcleos está o apoio na organização do trabalho pedagógico nos processos de inclusão.

Sendo assim, a relevância da pesquisa se justifica em termos acadêmicos e educacionais pouco explorados sobre o uso da tecnologia na deficiência visual na Educação Superior. Para tanto o presente artigo objetiva-se estudar a partilha de experiência sobre o uso das tecnologias desenvolvida por aluno deficiente visual com seus professores como estratégia para contribuir para o apoio do professor na sua organização do trabalho pedagógico com alunos deficientes visuais incluídos na Educação Superior.

\section{Metodologia}

Conforme Yin (2001) o estudo de caso é uma estratégia de pesquisa que compreende vários procedimentos para a coleta e análise de dados. O estudo foi exploratório e tratase de um subprojeto de uma pesquisa que estuda "os núcleos de apoio pedagógico no Ensino Superior". Para tanto foi utilizado nesta pesquisa Mantoan (2006) autora que nos abordará a inclusão.

Os sujeitos desta pesquisa foram uma aluna deficiente visual e seis professores de um curso superior de uma IES na Região Metropolitana do Rio Grande do Sul. Os sujeitos assinaram o Termo de Consentimento Livre e Esclarecido. Na presente investigação foi realizada observações durante três horas de cada dos três encontros sendo registradas em um diário de campo e buscando discutir a partilha de experiência sobre uso das tecnologias desenvolvida por aluno deficiente visual com seus professores. Dentre as tecnologias que a aluna utiliza como apoio na construção de sua aprendizagem foi escolhido o recurso tecnológico DosVox ${ }^{2}$ para ser desenvolvida partilha de experiências pela aluna.

\footnotetext{
${ }^{1} \mathrm{O}$ núcleo de apoio pedagógico, geralmente denominado Núcleo de Apoio Docente e Discente - NADD é um serviço que as instituições de na Educação Superior oportuniza para oferecer atendimento pedagógico, apoio psicopedagógico, orientação educacional e apoio no processo de educação inclusiva, sendo sua finalidade de auxiliar no processo de ensino e aprendizagem, bem como, no desenvolvimento pessoal e profissional do aluno.

${ }^{2}$ DosVox é um programa que pode ser instalado gratuitamente. O Núcleo de Computação Eletrônica da Universidade Federal do Rio de Janeiro (UFRJ) criador deste programa vem nos últimos anos se dedicando à criação de sistemas de computação para atender aos deficientes visuais. O sistema operacional DOSVOX permite que pessoas cegas utilizem um microcomputador comum (PC) para desempenhar uma série de tarefas, adquirindo assim um nível alto de independência no estudo e no trabalho.
} 
VI Congresso Brasileiro de Informática na Educação (CBIE 2017)

Anais dos Workshops do VI Congresso Brasileiro de Informática na Educação (WCBIE 2017)

\section{Contribuições Tecnológicas para o Ensino/Aprendizagem}

No segundo semestre de 2016 em uma faculdade, através do NADD, foi desenvolvida uma partilha de experiência com professores sobre a Deficiência Visual por uma aluna portadora desta deficiência que teve seu desenvolvimento da aprendizagem acompanhado por este setor. Durante os encontros com os professores foi desenvolvido estudo do recurso tecnológico do DosVox onde os professores conheceram as funções do programa e de como executá-lo.

No decorrer dos encontros realizam-se partilha de experiências sobre o processo de ensino e de aprendizagem com o uso da tecnologia na inclusão, mas em especial das funcionalidades do DosVox como potencializador da aprendizagem para facilitar os processos de inclusão e oportunizar leitura de leitura de textos, pesquisas e outros acessos de conhecimento por meio da leitura. A aluna partilhou sua experiência com o uso da tecnologia como apoio para aprendizagem. Salientou que na trajetória de sua aprendizagem a tecnologia contribuiu para o seu processo de inclusão permitindo potencializar suas capacidades. Professores relataram que se sentiram curiosos, motivados e acolhidos em aprender sobre os processos de inclusão com uma aluna deficiente visual.

Durante os encontros foi possível evidenciar falas dos professores onde buscaram trazer a importância do desenvolvimento de ações educacionais pedagógicas com eles sobre os processos de inclusão. Participar do desenvolvimento pedagógico dos processos de inclusão é um compromisso que segundo um professor que deve objetivarse buscar construir oportunidades para reflexão da prática da docência. Nestes processos também foi salientado pelos professores que devem também abordar a reflexão sobre a importância do uso das tecnologias para o planejamento de ações que promovam o desenvolvimento de novas metodologias de ensino.

Trata-se de uma nova formação, que busca aprimorar o que o professor já aprendeu em sua formação inicial, ora, fazendo-o tomar consciência de suas limitações, de seus talentos e competências, ora, suplementando esse saber pedagógico com outros, mais específicos, como o sistema braile, as técnicas de comunicação e de mobilidade alternativa/aumentativa, ora aperfeiçoando a sua maneira de ensinar os conteúdos curriculares, ora levando-o a refletir sobre as áreas do conhecimento, as tendências da sociedade contemporânea, ora fazendo-o provar de tudo isso, ao aprender a trabalhar com as tecnologias da educação... (MANTOAN, 2011)

$\mathrm{Na}$ educação superior para outro professor que participou dos encontros, a transversalidade da educação especial se constrói por meio de ações que promovam não só o acesso e a permanência, mas a participação dos alunos em uma educação inclusiva de um ensino de qualidade e o uso das tecnologias permitem contribuir. O conhecimento pedagógico do uso das tecnologias para o grupo de professores busca o planejamento e organização para a promoção da aprendizagem dos alunos de inclusão com apoio didático e pedagógico desenvolvido nos processos de inclusão.

\section{Considerações Finais}

Percebemos que a construção de ações pedagógicas com professores com das tecnologias como estratégias pode contribuir para a aprendizagem de alunos com 
deficiência visual incluídos na Educação Superior. É durante a partilha e busca de conhecimentos sobre os processos de inclusão da deficiência visual na Educação Superior que é reconhecida a necessidade do conhecimento pedagógica no uso das tecnologias e este apoio pode advir da partilha de experiência desenvolvida por aluno deficiente visual para construir estratégias de aprendizagens sobre o uso da tecnologia nos processos de inclusão. Sendo assim, as a construção de ações pedagógicas com professores no processo de inclusão na educação superior sobre a deficiência visual é uma temática desafiadora que necessita de apoio para sua construção.

\section{Referências}

MANTOAN, Maria Teresa Eglér. A educação especial no Brasil: da exclusão à inclusão escolar. 2011. Disponível em: http://www.lite.fe.unicamp.br/cursos/nt/ta1.3.htm. Acessado em 23 de junho de 2017.

MOLIN, Suênia Izabel Lino. RAABE, André Raabe. Novas Tecnologias n Educação: Transformações da Prática Pedagógica no Discurso Do Professor. Anais do XVIII ${ }^{\circ}$ Simpósio Brasileiro de Informática na Educação (SBIE 2012). Disponível em: http://www.br-ie.org/pub/index.php/wie/article/view/2104/1870. Acessado em 20 de junho de 2017.

PALAZZO, Luiz A. M. COSTA, Antônio C. R. DIMURO, Graçaliz P. SCHIRMBECK, Fernando. Comunidades Virtuais de Formação Tecnológica: Fundamentação Pedagógica e Metodologia de Construção. Anais do XVIII ${ }^{\circ}$ Simpósio Brasileiro de Informática na Educação (SBIE 2002). Disponível em: http://www.br-ie.org/pub/index.php/sbie/article/view/175/161. Acessado em 15 de junho de 2017.

RIBEIRO, Mônica Norris. VIEIRA, Alessandro Carra. GERALDO, Luciano Pereira. Formação de administradores Moodle no contexto UCA: uma experiência de criação de salas de aula virtuais como recurso para o atendimento ao proposto na Lei 11.738/08. Anais do XVIII ${ }^{\circ}$ Simpósio Brasileiro de Informática na Educação (SBIE 2014). Disponível em: http://www.brie.org/pub/index.php/wie/article/view/3099/2607. Acessado em 24 de junho de 2017.

YIN, Robert K. Estudo de caso: planejamento e métodos/ Robert K. Yin; trad. Daniel Grassi - 2.ed. -Porto Alegre: Bookman, 2001. 